\title{
Bioinformatics analysis of biomarkers and transcriptional factor motifs in Down syndrome
}

\author{
X.D. Kong, N. Liu and X.J. Xu
}

Prenatal Diagnosis Center, the First Affiliated Hospital, Zhengzhou University, Zhengzhou, China

\begin{abstract}
In this study, biomarkers and transcriptional factor motifs were identified in order to investigate the etiology and phenotypic severity of Down syndrome. GSE 1281, GSE 1611, and GSE 5390 were downloaded from the gene expression ominibus (GEO). A robust multiarray analysis (RMA) algorithm was applied to detect differentially expressed genes (DEGs). In order to screen for biological pathways and to interrogate the Kyoto Encyclopedia of Genes and Genomes (KEGG) pathway database, the database for annotation, visualization, and integrated discovery (DAVID) was used to carry out a gene ontology (GO) function enrichment for DEGs. Finally, a transcriptional regulatory network was constructed, and a hypergeometric distribution test was applied to select for significantly enriched transcriptional factor motifs. CBR1, DYRK1A, HMGN1, ITSN1, RCAN1, SON, TMEM5OB, and TTC3 were each up-regulated two-fold in Down syndrome samples compared to normal samples; of these, SON and TTC3 were newly reported. CBR1, DYRK1A, HMGN1, ITSN1, RCAN1, SON, TMEM50B, and TTC3 were located on human chromosome 21 (mouse chromosome 16). The DEGs were significantly enriched in macromolecular complex subunit organization and focal adhesion pathways. Eleven significantly enriched transcription factor motifs ( $P A X 5$, EGR1, XBP1, SREBP1, OLF1, MZF1, NFY, NFKAPPAB, MYCMAX, NFE2, and RP58) were identified. The DEGs and transcription factor motifs identified in our study provide biomarkers for the understanding of Down syndrome pathogenesis and progression.
\end{abstract}

Key words: Down syndrome; Candidate gene; Biomarker; Transcriptional factor motifs

\section{Introduction}

Down syndrome, the most frequent genetic cause of mental retardation occurring in newborns, results from the presence of three copies of chromosome 21 (trisomy 21) (1). This imbalance of 300 genes causes dysfunctions in developmental and physiological processes, leading to a complex phenotype defined by several clinical features, which are variable in their number and intensity (2). It is typically associated with physical growth delays, a particular set of facial characteristics, and a severe degree of intellectual disability (3). Children with Down syndrome may have severe mental retardation (4) and developmental delay, and they are prone to gastrointestinal malformations (5). At present, there is no effective drug for treatment of the disease, and, because prenatal diagnosis is the most effective way to avoid the birth of children with Down syndrome, it is important to study the pathogenesis of this disease.

A change in gene expression occurs in trisomy 21 (6). Antonarakis et al. showed that some characteristics of the
Down syndrome phenotype can be related to an increase in expression of two HSA21 genes: DSCR1-RCAN1 (regulator of calcineurin activity 1) and the protein kinase DYRK1A (dual-specificity tyrosine phosphorylationregulated kinase). In the developing brain, candidate genes would be involved in neurogenesis, neuronal differentiation, myelination, or synaptogenesis (7). In Down syndrome, aberrant expression of CRLF2 is associated with mutated JAK2, suggesting that blocking the CRLF2/JAK2 pathway may be an effective method for Down syndrome therapy (8).

Because the abnormal copy number of chromosome 21 is the main genetic characteristic of the disease, we applied a variety of bioinformatics tools to determine biomarkers of Down syndrome and the transcriptional regulatory network. In the process of identifying differentially expressed genes (DEGs), those genes that showed the greatest up-regulation were selected as biomarkers for Down syndrome. GO (gene ontology) function and

Correspondence: X.D. Kong, Prenatal Diagnosis Center, the First Affiliated Hospital, Zhengzhou University, Jiangshe Donglu \#1, Zhengzhou, Henan 450052, China. E-mail: kongxd@263.net 
Kyoto Encyclopedia of Genes and Genomes (KEGG) enrichment for DEGs were used to identify the significantly enriched biological terms and pathways. Finally, a hypergeometric distribution test was applied to select the significantly enriched motifs by transcriptional regulatory network construction.

\section{Material and Methods}

\section{Data source}

Raw gene expression data of Down syndrome samples and normal samples were downloaded from the Gene Expression Omnibus (GEO) (http://www.ncbi. nlm.nih.gov/geo/) of the National Center for Biotechnology Information (NCBI). GSE 1281 (9) and GSE 1611 (10) were from the following GLP81 platform: Affymetrix Murine Genome U74A Version 2 Array. GSE 1281 included six Down syndrome samples and six normal samples, which were from newborn rat brain tissue; GSE 1611 contained 12 samples (Ts1Cje and euploid Down syndrome cerebellum) as follows: two Down syndrome samples at postnatal days 15 and 30 , respectively, and two normal samples of newborn at postnatal days 15 and 30, respectively. GSE 5390 (11) was from the following GPL96 platform: [HG-U133A] Affymetrix Human Genome U133A Array, including seven Down syndrome samples from adult humans with Down syndrome and eight normal samples.

\section{Data preprocessing}

The robust multiarray analysis (RMA) algorithm (12) in Affymetrix Power Tools (APT; http://www.affymetrix.com/) was applied to perform background correction and standardization for all raw data, aiming to filter falsepositive data. The applied criterion was as follows: at least half the samples had PLIER signal intensity values greater than $100(13,14)$.

\section{Screening of DEGs}

The screening criteria for DEGs were as follows: signal intensity of Down syndrome samples to normal samples was up-regulated or down-regulated 1.2 times (RMA conversion was $0.26 ; \mathrm{P}<0.05)$, and there was at least one group in which the PLIER signal intensity value of half the samples was greater than 100 . In order to obtain more DEGs, data in GSE 1281 and GSE 1611 were integrated and normalization performed, while differential analysis of data in different tissue and development stages of Down syndrome samples compared with normal samples were performed separately, and then differential results were combined. We screened up- and down-regulated genes according to the sequence conservation (15) in human and rat brains. Finally, the genes showing the greatest degree of up-regulation (such as the genes whose signal intensity increased or decreased 1.5 times and with RMA conversion values greater than 0.58 ) were selected for study.

\section{Gene function annotation}

The database for annotation, visualization, and integrated discovery (DAVID) (16) was applied to perform GO function enrichment for DEGs with signal intensity increased or decreased 1.2 times and with RMA where the conversion value was greater than 0.26 , and then the significantly enriched $\mathrm{GO}$ terms $[\mathrm{P} \leq 0.05$, false discovery rate $(F D R) \leq 10]$ and KEGG pathways $(P \leq 0.05)$ were identified.

\section{Construction of the transcriptional regulatory network}

To construct the transcriptional regulatory network, the sequence from $1 \mathrm{~kb}$ upstream to $200 \mathrm{bp}$ downstream at the 5'UTR transcription start site of DEGs was extracted, and the JASPAR database (17) was used to search for transcription factor binding sites (score threshold: 0.95). In addition, because the JASPAR database is limited, the transcriptional regulatory network was constructed combined with transcription factor binding sites in the University of California Santa Cruz (USA) genome browser database (18). Finally, a hypergeometric distribution test (19) was applied to select the significantly enriched motifs ( $P \leq 0.01)$.

\section{Results}

\section{Identification of DEGs and biomarkers}

A total of 581 DEGs were identified, in which 227 DEGs were up-regulated and 354 DEGs were downregulated (Figure $1 \mathrm{~A})$. The distribution of DEGs in different development stages of Down syndrome is shown in Figure 1A. A total of 2180 DEGs were identified, in which 2010 were up-regulated and 800 were downregulated (Figure 1A).

Generally speaking, the relationship between the transcription factors and their regulatory target genes in human and mouse were conserved. A total of 50 upregulated and 23 down-regulated DEGs were identified according to orthologous relationships of human vs mouse. Nine up-regulated genes CDKN1C (cyclin-dependent kinase inhibitor 1C), DCN (decorin), HMGN1 (non-histone chromosomal protein HMG-14), HSD17B11 (estradiol 17beta-dehydrogenase 11), LGALS3BP (galectin-3-binding protein), MT2 (metallothionein-2R), RCAN1, SON [a large Ser/Arg (SR)-related protein], and XIST (X-inactive specific transcript) were up-regulated at least 1.5 times, and the RMA conversion value was greater than 0.58 .

\section{Distribution of DEGs in chromosomes}

Figure 2A demonstrates the distribution of 50 upregulated genes and 23 down-regulated genes in both human and mouse in the human chromosome. Eight genes of 50 up-regulated DEGs were distributed in human chromosome 21 (mouse chromosome 16), while no downregulated DEGs were distributed in human chromosome 21 
A
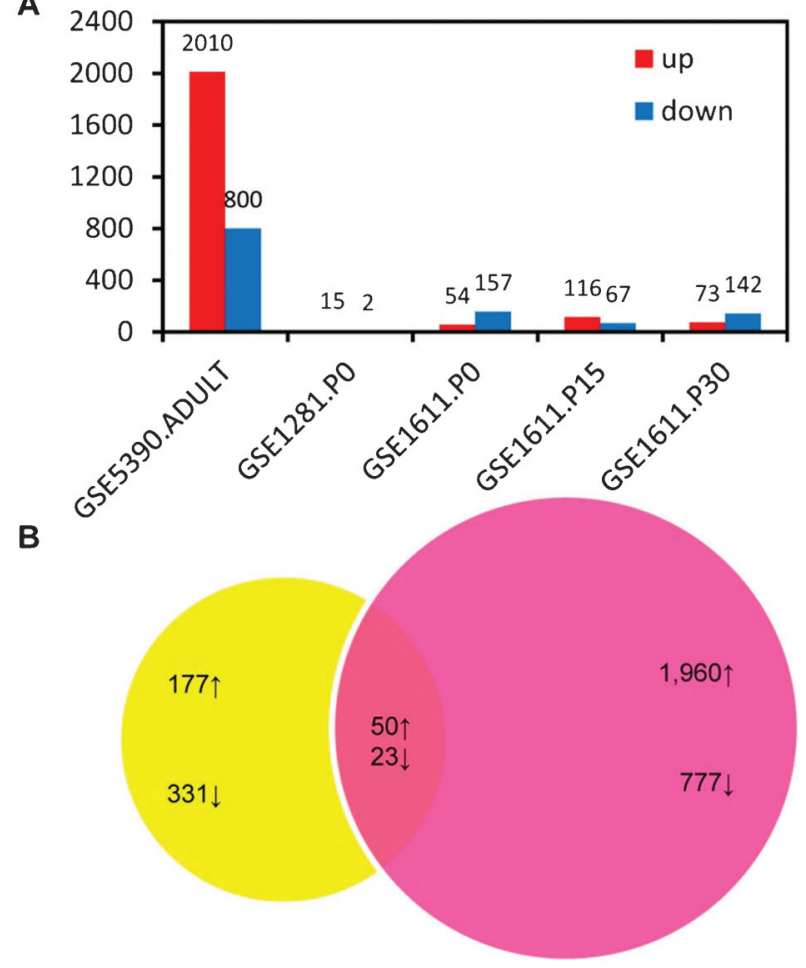

Mouse Human

Figure 1. $A$, Differentially expressed genes (DEGs) in Down syndrome samples compared with normal samples. $B$, Venn diagram of DEGs in human and mouse.

(Table 1). Molecular interactions of the following eight genes are shown in Figure 2B: CBR1 (carbonyl reductase 1), DYRK1A, HMGN1, ITSN1 [intersectin 1 (SH3 domain protein)], RCAN1, SON, TMEM5OB (transmembrane protein 50B), and TTC3 (tetratricopeptide repeat protein 3). Information on interactions was selected from the BIOGRID database (20), but TMEM50B had no interaction information.

\section{Gene function and KEGG pathway annotation}

The DAVID functional annotation of 73 DEGs is shown in Figure $3(P \leq 0.05$ and FDR $\leq 10)$. The most significantly enriched biological processes were macromolecular complex subunit organization, cellular ion homeostasis, and synaptic vesicle endocytosis (Table 2). A total of 73 KEGG pathways of DEGs is shown in Table $3(\mathrm{P} \leq 0.05)$. The most significantly enriched KEGG pathways were focal adhesion, natural killer cell mediated cytotoxicity, and Alzheimer's disease.

\section{Transcriptional regulatory network}

The transcriptional regulatory network was constructed according to ortholog genes in human and mouse. The significantly enriched transcription factors in the transcriptional regulatory network are shown in Figure 4A. Eleven significantly $(P \leq 0.01)$ enriched transcription factor motifs [PAX5 (paired box protein Pax-5), EGR1 (early growth response protein 1), XBP (X-box binding protein 1), SREBP1 (sterol regulatory element-binding transcription factor 1), OLF1 (human olfactory receptor), MZF1 (myeloid zinc finger 1), NFY, NFKAPPAB (nuclear factor kappa B), MYCMAX, NFE2 (transcription factor NF-E2 $45 \mathrm{kDa}$ subunit), and RP58] in the transcriptional regulatory network and three motifs in the JASPAR database (17) are shown in Figure 4B.

\section{Discussion}

Down syndrome is a genetic condition in which a person has 47 chromosomes instead of the usual 46 . In most cases, Down syndrome occurs when there is an extra copy of chromosome 21. In this study, we identified 581 DEGs in Down syndrome compared with normal tissue, and 8 DEGs were distributed in human chromosome 21. Finally, we identified 11 transcription factor motifs.

HMGN1, RCAN1, and SON were distributed in human chromosome 21. HMGN1 and RCAN1 have been reported to be associated with Down syndrome $(21,22)$, but the relationship between SON and Down syndrome has not been identified. HMGN1 could regulate expression of methyl CpG-binding protein 2 (MeCP2), and may lead to neurodevelopmental disorders (23). Up-regulated expression of RCAN1 was reported to cause Down

Table 1. The up-regulated genes observed in human (chromosome 21) and mouse (chromosome 16).

\begin{tabular}{|c|c|c|c|c|c|}
\hline Human probe & Human symbol & Human chromosome & Mouse probe & Mouse symbol & Mouse chromosome \\
\hline 209213_at & CBR1 & 21 & 96110_at & CBR1 & 16 \\
\hline 209033_s_at & DYRK1A & 21 & 104079_at & DYRK1A & 16 \\
\hline 200944_s_at & HMGN1 & 21 & 96699_at & HMGN1 & 16 \\
\hline 209297_at & ITSN1 & 21 & 104522_at & ITSN1 & 16 \\
\hline 215253_s_at & RCAN1 & 21 & 100555_at & RCAN1 & 16 \\
\hline 213538_at & SON & 21 & 94386_at & SON & 16 \\
\hline 219600_s_at & TMEM50B & 21 & 96340_at & TMEM50B & 16 \\
\hline 208664_s_at & TTC3 & 21 & 98555_at & TTC3 & 16 \\
\hline
\end{tabular}




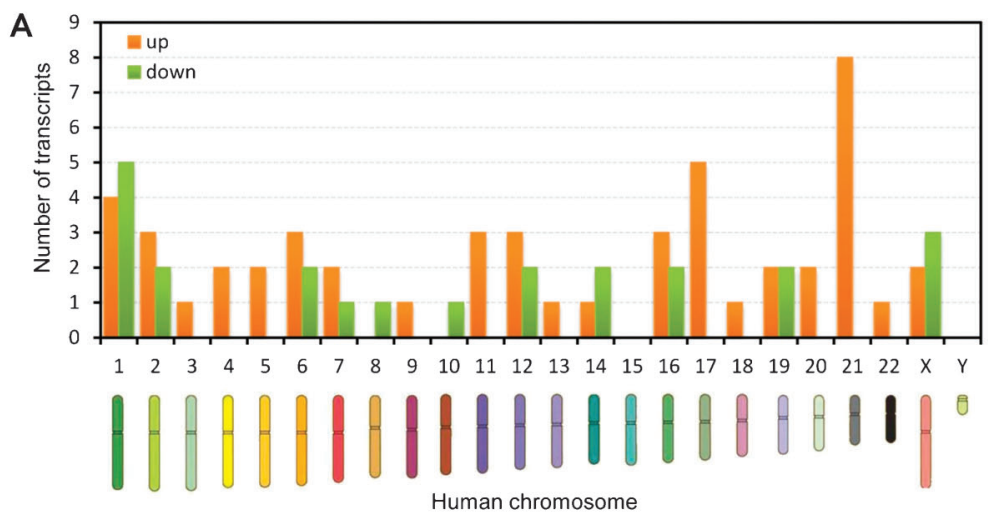

B

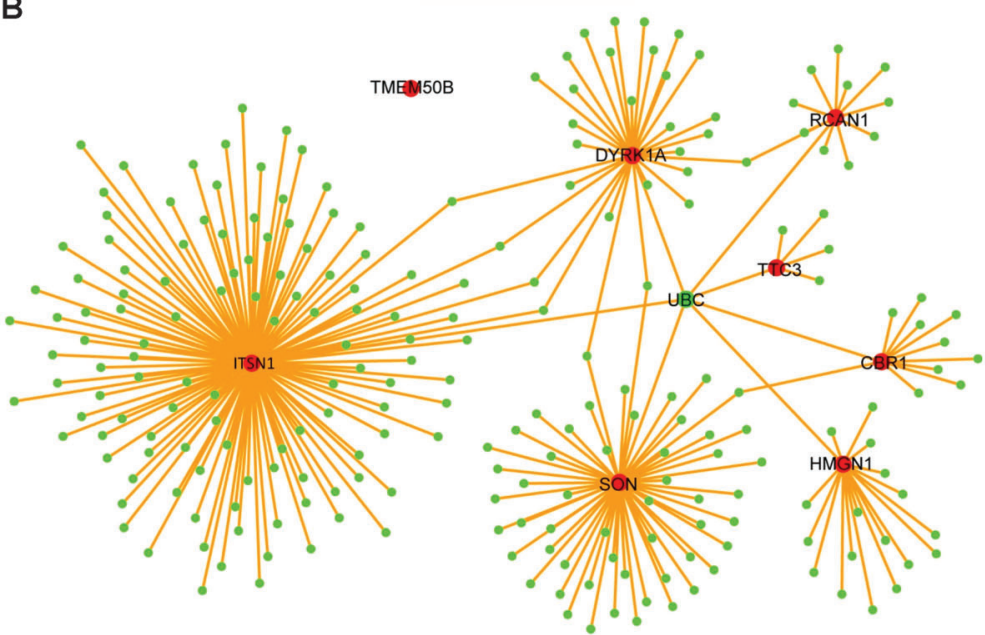

Figure 2. A, Distribution of homologous gene transcripts in both human and mouse in the human chromosome. $B$, Interaction networks of eight genes in chromosome 21 . Red nodes represent differentially expressed genes (DEGs), and green nodes represent non-DEGs. syndrome-like immune dysfunction (24). The differential expression of SON was significant during developmental stages in human and mouse (except postnatal day 15; others were more than 1.5 times). SON is an SR-type protein involved in mRNA processing and gene expression, which is a splicing cofactor that contributes to an efficient splicing within cell cycle progression (25). Some $\mathrm{SR}$ proteins have been reported to influence the selection

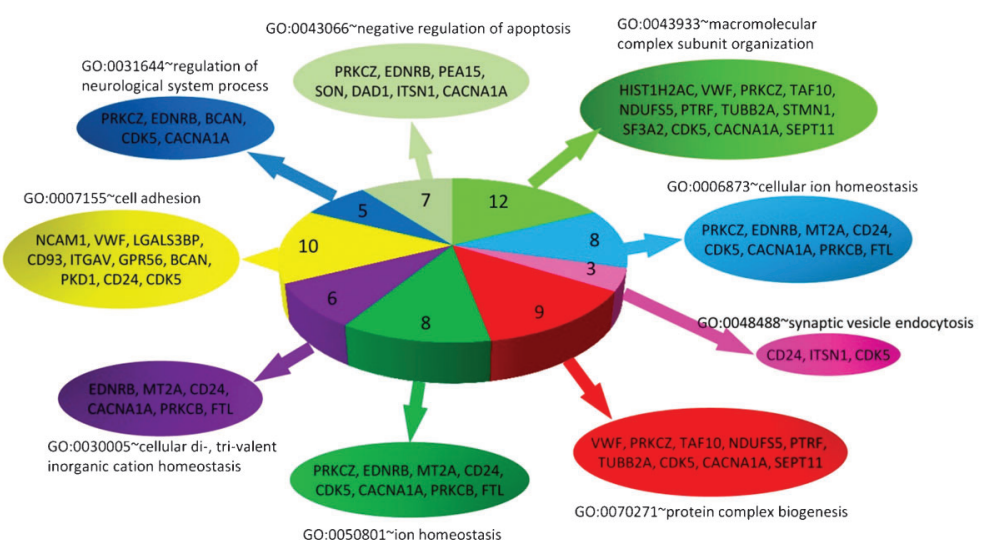

Figure 3. GO (gene ontology) enrichment analysis of 73 differentially expressed genes. 
Table 2. Gene ontology (GO) functional annotation of 73 differentially expressed genes.

\begin{tabular}{|c|c|c|c|}
\hline Term & $\mathrm{P}$ & Genes & FDR \\
\hline $\begin{array}{l}\text { GO: } 0043933 \sim \text { macromolecular complex } \\
\text { subunit organization }\end{array}$ & 2.91E-04 & $\begin{array}{l}\text { HIST1H2AC, VWF, PRKCZ, TAF10, NDUFS5, } \\
\text { PTRF, TUBB2A, STMN1, SF3A2, CDK5, } \\
\text { CACNA1A, SEPT11 }\end{array}$ & 0.46 \\
\hline GO: $0006873 \sim$ cellular ion homeostasis & $1.41 \mathrm{E}-03$ & $\begin{array}{l}\text { PRKCZ, EDNRB, MT2A, CD24, CDK5, } \\
\text { CACNA1A, PRKCB, FTL }\end{array}$ & 2.21 \\
\hline GO: 0048488 synaptic vesicle endocytosis & $1.76 \mathrm{E}-03$ & CD24, ITSN1, CDK5 & 2.75 \\
\hline GO: 0070271 protein complex biogenesis & $1.84 \mathrm{E}-03$ & $\begin{array}{l}\text { VWF, PRKCZ, TAF10, NDUFS5, PTRF, } \\
\text { TUBB2A, CDK5, CACNA1A, SEPT11 }\end{array}$ & 2.88 \\
\hline GO: 0050801 ion homeostasis & $2.34 \mathrm{E}-03$ & $\begin{array}{l}\text { PRKCZ, EDNRB, MT2A, CD24, } \\
\text { CDK5, CACNA1A, PRKCB, FTL }\end{array}$ & 3.65 \\
\hline $\begin{array}{l}\text { GO: } 0030005 \sim \text { cellular di-, tri-valent } \\
\text { inorganic cation homeostasis }\end{array}$ & $3.53 E-03$ & $\begin{array}{l}\text { EDNRB, MT2A, CD24, CACNA1A, } \\
\text { PRKCB, FTL }\end{array}$ & 5.45 \\
\hline GO: 0007155 cell adhesion & $3.91 \mathrm{E}-03$ & $\begin{array}{l}\text { NCAM1, VWF, LGALS3BP, CD93, } \\
\text { ITGAV, GPR56, BCAN, PKD1, CD24, CDK5 }\end{array}$ & 6.03 \\
\hline $\begin{array}{l}\text { GO: } 0031644 \sim \text { regulation of neurological } \\
\text { system process }\end{array}$ & $4.98 \mathrm{E}-03$ & PRKCZ, EDNRB, BCAN, CDK5, CACNA1A & 7.61 \\
\hline $\begin{array}{l}\text { GO: } 0043066 \sim \text { negative regulation of } \\
\text { apoptosis }\end{array}$ & $5.09 \mathrm{E}-03$ & $\begin{array}{l}\text { PRKCZ, EDNRB, PEA15, SON, } \\
\text { DAD1, ITSN1, CACNA1A }\end{array}$ & 7.77 \\
\hline
\end{tabular}

The nine highest-ranked terms showing significant differential expression are listed. FDR: false discovery rate.

of alternative $5^{\prime}$ splice sites (26). All results suggested that $S O N$ may most likely be a candidate gene.

Another five genes (CBR1, DYRK1A, ITSN1, TMEM50, and TTC3) were also distributed in human chromosome 21. A previous study reported that the mRNA level of CBR1 in Down syndrome samples was 1.8-fold greater than that in normal samples. In agerelated neurodegenerative diseases, DYRK1A can regulate the expression of RCAN1 (27). Trisomic mice injected in the hippocampus with short hairpin RNA against $D Y R K 1 A$ showed attenuation of synaptic plasticity defects (28). Recently, De la Torre et al. (29) reported that the DYRK1A inhibitor EGCG (the green tea flavonol, epigallocatechin gallate) could inhibit the activity of $D Y R K 1 A$ in the hippocampus area to prevent cognitive deficits in Down syndrome mouse models. ITSN and TMEM50 have been reported to be related to Down syndrome $(30,31)$. Although there is no literature about TTC3 and Down syndrome, TTC3 is related to another seven genes distributed in human chromosome 21 (32). Therefore, TTC3 is also a very likely candidate gene for Down syndrome.
In GO function annotation, some genes involved with regulation of neurological system processes were enriched in Down syndrome samples. Also, during KEGG pathway annotation, there were some genes related to Alzheimer's disease (a nervous system disease) (33). PRKCZ (potein kinase C, zeta), EDNRB (endothelin receptor type $\mathrm{B}$ ), CDK5 (cell division protein kinase 5), and CACNA1A (cav2.1 P/Q voltage-dependent calcium channel) were related to nervous system diseases. PRKCZ is thought to be responsible for maintaining long-term memory in the brain (34). EDNRB is a $\mathrm{G}$ protein-coupled receptor, which activates a phosphatidylinositol-calcium second messenger system (35). CDK5 is involved in the processes of neuronal maturation and migration, phosphorylating the key intracellular adaptors of the reelin signaling chain (36). CACNA1A is also involved in neurotransmitter release (37). These genes are involved in the nervous system and they are likely related to Down syndrome, and further studies are needed to confirm this.

In addition, 11 significantly enriched transcription factor motifs (PAX5, EGR1, XBP1, SREBP1, OLF1,

Table 3. KEGG pathway annotation of 73 differentially expressed genes.

\begin{tabular}{lccc}
\hline Pathway term & $\mathrm{P}$ & Genes & FDR \\
\hline hsa04510: focal adhesion & $1.28 \mathrm{E}-02$ & ACTB, VWF, ITGAV, MAPK3, COL1A2, PRKCB & 13.35 \\
hsa04650: natural killer cell mediated cytotoxicity & $1.38 \mathrm{E}-02$ & MAPK3, PPP3R1, HLA-B, HLA-E, PRKCB & 14.35 \\
hsa05010: Alzheimer's disease & $2.70 \mathrm{E}-02$ & NDUFS5, NDUFA9, MAPK3, PPP3R1, CDK5 & 26.32 \\
hsa04930: type II diabetes mellitus & $4.32 \mathrm{E}-02$ & PRKCZ, MAPK3, CACNA1A & 38.89 \\
\hline
\end{tabular}

The four highest-ranked terms showing significant differential expression are listed. FDR: false discovery rate. 


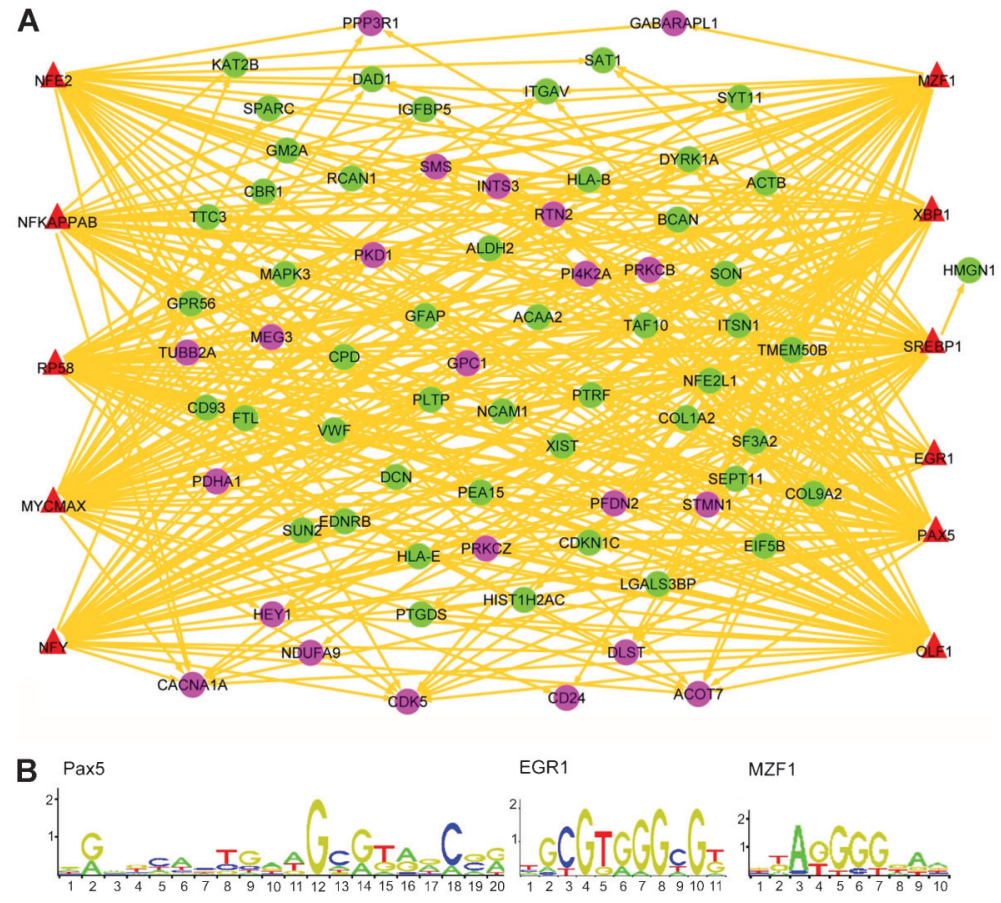

Figure 4. $A$, Transcriptional regulatory network of up-regulated or down-regulated genes. Red triangles denote transcription factors; green circles denote up-regulated genes; pink circles denote down-regulated genes. $B$, Significantly enriched transcription factor motifs of up-regulated or down-regulated genes in JASPAR database.

MZF1, NFY, NFKAPPAB, MYCMAX, NFE2, RP58) were identified. XBP1, SREBP1, OLF1, NFY, NFKAPPAB, $M Y C M A X, N F E 2$, and RP58 were reportedly not associated with nervous system disease, whereas, in children with Down syndrome and acute lymphoblastic leukemia, $P A X 5$ was found to be missing (38). Combined with our results, we considered that $P A X 5$ may be involved in Down syndrome. In the hippocampus region of simian immunodeficiency virus encephalitis-induced neural dysfunction, EGR1 is down-regulated (39). MZF1 is predominantly expressed in neuronal tissue, and mutations

\section{References}

1. Van Gameren-Oosterom HB, Fekkes M, Van Wouwe JP, Detmar SB, Oudesluys-Murphy AM, Verkerk PH. Problem behavior of individuals with Down syndrome in a nationwide cohort assessed in late adolescence. J Pediatr 2013; 163: 1396-1401, doi: 10.1016/j.jpeds.2013.06.054.

2. Epstein CJ, Korenberg JR, Anneren G, Antonarakis SE, Ayme S, Courchesne E, et al. Protocols to establish genotype-phenotype correlations in Down syndrome. Am J Hum Genet 1991; 49: 207-235.

3. Stochholm K, Juul S, Juel K, Naeraa RW, Gravholt CH. Prevalence, incidence, diagnostic delay, and mortality in Turner syndrome. J Clin Endocrinol Metab 2006; 91: 38973902, doi: 10.1210/jc.2006-0558.

4. Weiss M. Conditional love: parent's attitudes toward handicapped children. Westport: Greenwood Publishing Group; 1994. in this gene are associated with neurological disorders providing a potential link between this kinase and neurodegeneration (40).

In conclusion, CBR1, DYRK1A, HMGN1, ITSN1, RCAN1, SON, TMEM50B, and TTC3 may be related to Down syndrome, and SON and TTC3 were newly reported in our study. Also, the transcription factor motifs PAX5, EGR1, XBP1, SREBP1, OLF1, MZF1, NFY, NFKAPPAB, MYCMAX, NFE2, and RP58 may contribute to the pathology of Down syndrome. However, further study is needed to confirm our results.

5. Ward OC. John Langdon Down: the man and the message. Downs Syndr Res Pract 1999; 6: 19-24, doi: 10.3104/ perspectives.94.

6. Antonarakis SE, Lyle R, Dermitzakis ET, Reymond A, Deutsch S. Chromosome 21 and down syndrome: from genomics to pathophysiology. Nat Rev Genet 2004; 5: 725738, doi: 10.1038/nrg1448.

7. FitzPatrick DR, Ramsay J, McGill NI, Shade M, Carothers AD, Hastie ND. Transcriptome analysis of human autosomal trisomy. Hum Mol Genet 2002; 11: 3249-3256, doi: $10.1093 / \mathrm{hmg} / 11.26 .3249$

8. Hertzberg L, Vendramini E, Ganmore I, Cazzaniga G, Schmitz M, Chalker J, et al. Down syndrome acute lymphoblastic leukemia, a highly heterogeneous disease in which aberrant expression of CRLF2 is associated with mutated JAK2: a report from the International BFM Study 
Group. Blood 2010; 115: 1006-1017, doi: 10.1182/blood2009-08-235408.

9. Amano K, Sago H, Uchikawa C, Suzuki T, Kotliarova SE, Nukina $\mathrm{N}$, et al. Dosage-dependent over-expression of genes in the trisomic region of Ts1Cje mouse model for Down syndrome. Hum Mol Genet 2004; 13: 1333-1340, doi: 10.1093/hmg/ddh154.

10. Dauphinot L, Lyle R, Rivals I, Dang MT, Moldrich RX, Golfier G, et al. The cerebellar transcriptome during postnatal development of the Ts1Cje mouse, a segmental trisomy model for Down syndrome. Hum Mol Genet 2005; 14: 373-384, doi: 10.1093/hmg/ddi033.

11. Lockstone HE, Harris LW, Swatton JE, Wayland MT, Holland AJ, Bahn S. Gene expression profiling in the adult Down syndrome brain. Genomics 2007; 90: 647-660, doi: 10.1016/j.ygeno.2007.08.005.

12. Irizarry RA, Hobbs B, Collin F, Beazer-Barclay YD, Antonellis KJ, Scherf $U$, et al. Exploration, normalization, and summaries of high density oligonucleotide array probe level data. Biostatistics 2003; 4: 249-264, doi: 10.1093/ biostatistics/4.2.249.

13. $\mathrm{Qu} \mathrm{Y}, \mathrm{He} F$, Chen $\mathrm{Y}$. Different effects of the probe summarization algorithms PLIER and RMA on high-level analysis of Affymetrix exon arrays. BMC Bioinformatics 2010; 11: 211, doi: 10.1186/1471-2105-11-211.

14. Wang $\mathrm{K}$, Wang $\mathrm{H}$, Wang $\mathrm{J}$, Xie $\mathrm{Y}$, Chen J, Yan $\mathrm{H}$, et al. System approaches reveal the molecular networks involved in neural stem cell differentiation. Protein Cell 2012; 3: 213224, doi: 10.1007/s13238-012-0014-4.

15. Sahoo D, Seita J, Bhattacharya D, Inlay MA, Weissman IL, Plevritis SK, et al. MiDReG: a method of mining developmentally regulated genes using Boolean implications. Proc Natl Acad Sci U S A 2010; 107: 5732-5737, doi: 10.1073/pnas.0913635107.

16. Huang da W, Sherman BT, Lempicki RA. Systematic and integrative analysis of large gene lists using DAVID bioinformatics resources. Nat Protoc 2009; 4: 44-57, doi: 10.1038/nprot.2008.211

17. Portales-Casamar E, Thongjuea S, Kwon AT, Arenillas D, Zhao X, Valen E, et al. JASPAR 2010: the greatly expanded open-access database of transcription factor binding profiles. Nucleic Acids Res 2010; 38: D105-D110, doi: 10.1093/ nar/gkp950.

18. Fujita PA, Rhead B, Zweig AS, Hinrichs AS, Karolchik D, Cline MS, et al. The UCSC Genome Browser database: update 2011. Nucleic Acids Res 2011; 39: D876-D882, doi: 10.1093/nar/gkq963.

19. Wang $\mathrm{K}$, Hu F, Xu K, Cheng $\mathrm{H}$, Jiang M, Feng $\mathrm{R}$, et al. CASCADE_SCAN: mining signal transduction network from high-throughput data based on steepest descent method. BMC Bioinformatics 2011; 12: 164, doi: 10.1186/1471-210512-164.

20. Stark C, Breitkreutz BJ, Chatr-Aryamontri A, Boucher L, Oughtred R, Livstone MS, et al. The BioGRID Interaction Database: 2011 update. Nucleic Acids Res 2011; 39: D698D704, doi: 10.1093/nar/gkq1116.

21. Birger $Y$, West KL, Postnikov YV, Lim JH, Furusawa T, Wagner JP, et al. Chromosomal protein HMGN1 enhances the rate of DNA repair in chromatin. EMBO $J$ 2003; 22: 1665-1675, doi: 10.1093/emboj/cdg142.

22. Fuentes JJ, Genesca L, Kingsbury TJ, Cunningham KW,
Perez-Riba M, Estivill X, et al. DSCR1, overexpressed in Down syndrome, is an inhibitor of calcineurin-mediated signaling pathways. Hum Mol Genet 2000; 9: 1681-1690, doi: $10.1093 / \mathrm{hmg} / 9.11 .1681$.

23. Abuhatzira L, Shamir A, Schones DE, Schaffer AA, Bustin $M$. The chromatin-binding protein HMGN1 regulates the expression of methyl CpG-binding protein 2 (MECP2) and affects the behavior of mice. J Biol Chem 2011; 286: 4205142062, doi: 10.1074/jbc.M111.300541.

24. Stefos GC, Soppa U, Dierssen M, Becker W. NGF upregulates the plasminogen activation inhibitor-1 in neurons via the calcineurin/NFAT pathway and the Down syndrome-related proteins DYRK1A and RCAN1 attenuate this effect. PLoS One 2013; 8: e67470, doi: 10.1371/ journal.pone.0067470.

25. Ahn EY, DeKelver RC, Lo MC, Nguyen TA, Matsuura S, Boyapati A, et al. SON controls cell-cycle progression by coordinated regulation of RNA splicing. Mol Cell 2011; 42: 185-198, doi: 10.1016/j.molcel.2011.03.014.

26. Wynn SL, Fisher RA, Pagel C, Price M, Liu QY, Khan IM, et al. Organization and conservation of the GART/SON/ DONSON locus in mouse and human genomes. Genomics 2000; 68: 57-62, doi: 10.1006/geno.2000.6254.

27. Song WJ, Song EA, Choi SH, Baik HH, Jin BK, Kim JH, et al. Dyrk1A-mediated phosphorylation of RCAN1 promotes the formation of insoluble RCAN1 aggregates. Neurosci Lett 2013; 554: 135-140, doi: 10.1016/j.neulet.2013.08.066.

28. Altafaj X, Martin ED, Ortiz-Abalia J, Valderrama A, LaoPeregrin C, Dierssen $M$, et al. Normalization of Dyrk1A expression by AAV2/1-shDyrk1A attenuates hippocampaldependent defects in the Ts65Dn mouse model of Down syndrome. Neurobiol Dis 2013; 52: 117-127, doi: 10.1016/ j.nbd.2012.11.017.

29. de la Torre R, De Sola S, Pons M, Duchon A, de Lagran $\mathrm{MM}$, Farre $\mathrm{M}$, et al. Epigallocatechin-3-gallate, a DYRK1A inhibitor, rescues cognitive deficits in Down syndrome mouse models and in humans. Mol Nutr Food Res 2014; 58: 278-288, doi: 10.1002/mnfr.201300325.

30. Keating DJ, Chen C, Pritchard MA. Alzheimer's disease and endocytic dysfunction: clues from the Down syndromerelated proteins, DSCR1 and ITSN1. Ageing Res Rev 2006; 5: 388-401, doi: 10.1016/j.arr.2005.11.001.

31. Moldrich RX, Laine J, Visel A, Beart PM, Laffaire J, Rossier $\mathrm{J}$, et al. Transmembrane protein 50b (C21orf4), a candidate for Down syndrome neurophenotypes, encodes an intracellular membrane protein expressed in the rodent brain. Neuroscience 2008; 154: 1255-1266, doi: 10.1016/j. neuroscience.2008.01.089.

32. Martin KR, Layton D, Seach N, Corlett A, Barallobre MJ, Arbones ML, et al. Upregulation of RCAN1 causes Down syndrome-like immune dysfunction. J Med Genet 2013; 50: 444-454, doi: 10.1136/jmedgenet-2013-101522.

33. Thies W, Bleiler L. 2011 Alzheimer's disease facts and figures. Alzheimers Dement 2011; 7: 208-244, doi: 10.1016/ j.jalz.2011.02.002.

34. Lee AM, Kanter BR, Wang D, Lim JP, Zou ME, Qiu C, et al. Prkcz null mice show normal learning and memory. Nature 2013; 493: 416-419, doi: 10.1038/nature11803.

35. Barlow A, de Graaff E, Pachnis V. Enteric nervous system progenitors are coordinately controlled by the $G$ proteincoupled receptor EDNRB and the receptor tyrosine kinase 
RET. Neuron 2003; 40: 905-916, doi: 10.1016/S08966273(03)00730-X.

36. Patrick GN, Zukerberg L, Nikolic M, de la Monte S, Dikkes P, Tsai LH. Conversion of p35 to p25 deregulates Cdk5 activity and promotes neurodegeneration. Nature 1999; 402: 615-622, doi: 10.1038/45159.

37. Fletcher CF, Tottene A, Lennon VA, Wilson SM, Dubel SJ, Paylor R, et al. Dystonia and cerebellar atrophy in Cacna1a null mice lacking $P / Q$ calcium channel activity. FASEB $J$ 2001; 15: 1288-1290.

38. Lundin C, Hjorth L, Behrendtz M, Nordgren A, Palmqvist L, Andersen MK, et al. High frequency of BTG1 deletions in acute lymphoblastic leukemia in children with down syndrome. Genes Chromosomes Cancer 2012; 51: 196206, doi: 10.1002/gcc.20944.

39. Gersten M, Alirezaei M, Marcondes MC, Flynn C, Ravasi T, Ideker $\mathrm{T}$, et al. An integrated systems analysis implicates EGR1 downregulation in simian immunodeficiency virus encephalitis-induced neural dysfunction. J Neurosci 2009 29: 12467-12476, doi: 10.1523/JNEUROSCI.3180-09.2009.

40. Gaboli M, Kotsi PA, Gurrieri C, Cattoretti G, Ronchetti S, Cordon-Cardo C, et al. Mzf1 controls cell proliferation and tumorigenesis. Genes Dev 2001; 15: 1625-1630, doi: $10.1101 /$ gad. 902301 . 